\title{
Preparation of Porous Poly(Styrene-Divinylbenzene) Microspheres and Their Modification with Diazoresin for Mix-Mode HPLC Separations
}

\author{
Bing Yu ${ }^{1,2}$, Tao Xu ${ }^{1}$, Hailin Cong ${ }^{1,2, *}$, Qiaohong Peng ${ }^{1}$ and Muhammad Usman ${ }^{1}$ \\ 1 Institute of Biomedical Materials and Engineering, College of Chemistry and Chemical Engineering, \\ Qingdao University, Qingdao 266071, China; yubingqdu@yahoo.com (B.Y.); amnano@163.com (T.X.); \\ weljoe@163.com (Q.P.); usman.latif21@gmail.com (M.U.) \\ 2 Laboratory for New Fiber Materials and Modern Textile, Growing Base for State Key Laboratory, \\ College of Materials Science and Engineering, Qingdao University, Qingdao 266071, China \\ * Correspondence: hailincong@yahoo.com; Tel.: +86-532-85953995; Fax: +86-532-85955529
}

Academic Editor: Dominik Brühwiler

Received: 8 February 2017; Accepted: 20 April 2017; Published: 22 April 2017

\begin{abstract}
By using the two-step activated swelling method, monodisperse porous poly(styrenedivinylbenzene) (P(S-DVB)) microparticles were successfully synthesized. The influence of porogens, swelling temperatures and crosslinking agents on the porosity of porous microparticles was carefully investigated. Porous $\mathrm{P}(\mathrm{S}-\mathrm{DVB})$ microparticles were used as a packing material for high performance liquid chromatography (HPLC). Several benzene analogues were effectively separated in a stainless-steel column as short as $75 \mathrm{~mm}$ due to the high specific surface area of the porous microparticles. Porous P(S-DVB) microparticles were further sulfonated and subsequently modified with diazoresin (DR) via electrostatic self-assembly and UV (ultraviolet) radiation. After treatment with UV light, the ionic bonding between sulfonated P(S-DVB) and DR was converted into covalent bonding through a unique photochemistry reaction of DR. Depending on the chemical structure of DR and mobile phase composition, the DR-modified P(S-DVB) stationary phase performed different separation mechanisms, including reversed phase (RP) and hydrophilic interactions. Therefore, baseline separations of benzene analogues and organic acids were achieved by using the DR-modified $\mathrm{P}(\mathrm{S}-\mathrm{DVB})$ particles as packing materials in HPLC. According to the $\pi-\pi$ interactional difference between carbon rings of fullerenes and benzene rings of $D R, C_{60}$ and $C_{70}$ were also well separated in the HPLC column packed with DR-modified P(S-DVB) particles.
\end{abstract}

Keywords: polystyrene; seeded polymerization; macroporous structures; diazoresin; high performance liquid chromatography

\section{Introduction}

In the last few decades, a lot of investigation has been done on the synthesis and properties of porous $\mathrm{P}(\mathrm{S}-\mathrm{DVB})$ beads. The activated swelling method, developed by Ugelstad et al. was utilized for the synthesis of monodisperse porous particles in the range of 1-20 $\mu \mathrm{m}$ [1-3]. Recently, a lot of research has been conducted to study the different properties of monodisperse polystyrene microspheres with porous structure [4-11], since they have high specific surface area, tunable pore morphology, mechanical stability and strong adsorption [12-14]. The widely-used techniques for the synthesis of porous $\mathrm{P}(\mathrm{S}-\mathrm{DVB})$ beads include activated swelling [15], seeded emulsion polymerization [16], precipitation polymerization [17], template imprinting [18,19] and membrane techniques [20,21].

Due to lower back pressure, a more regular flow regime in the column and higher resolutions, which result from their excellent permeability and high surface area, the monodisperse 
microspheres with porous structures have been widely used in chromatographic columns as packing materials [22-27]. For example, Unsal et al. [28] investigated the effect of the monomer/seed latex ratio for the chromatographic performance of monodisperse porous particles produced by a modified seeded polymerization method. Fréchet et al. [29-32] explored the impact of different surface chemistries of monodisperse macroporous particles on the chromatographic behavior.

In this paper, we synthesized monodisperse porous $\mathrm{P}(\mathrm{S}-\mathrm{DVB})$ microspheres by utilizing the activated swelling technique and investigated the effect of the porogen ratio, temperature and crosslinking agents. The porous $\mathrm{P}(\mathrm{S}-\mathrm{DVB})$ microparticles were further sulfonated with concentrated sulfuric acid and subsequently modified with diazoresin(DR)via electrostatic self-assembly and UV (ultraviolet) radiation. These porous microspheres were applied as column packing material in mix-mode HPLC analysis of benzene analogs, organic acids and fullerenes.

\section{Results and Discussion}

\subsection{Synthesis of Porous $P(S-D V B)$ Microparticles}

As illustrated in Figure 1, the synthesis process of monodisperse porous polymer microparticles was based on monodisperse linear polystyrene(PS) seed particles, undergoing porogen swelling, monomer and crosslinker swelling, polymerization and extraction. Monodisperse PS seed particles prepared by dispersion polymerization have an average diameter of $2.7 \mu \mathrm{m}$, and the coefficient of deviation $(\mathrm{CV})$ is only about $1.9 \%$ (Figure 2). The monodispersity was inherited when porous polymer microparticles were prepared. Dibutyl phthalate (DBP) is a seed swelling activator and porogen is a classical plasticizer. Toluene as a porogen is an excellent solvent of polystyrene. These two organic solvents can be diffused into PS seed particles from their emulsion. After being swollen with porogen, monomer, crosslinker and initiator, polymerization occurs in the seed particles to form an interpenetrating polymer network. Linear PS and porogens stay in the crosslinked polymer network and are then extracted by tetrahydrofuran (THF) to generate the porous structure. The preparation conditions of porous polymer microparticles are summarized in Table 1.

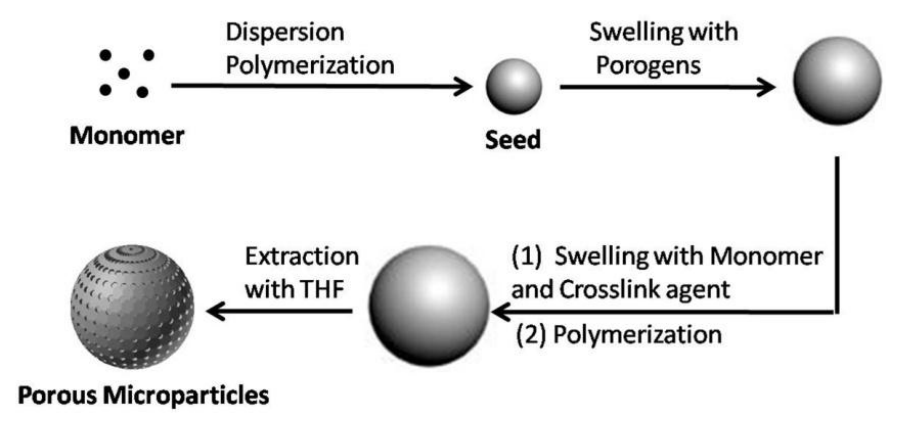

Figure 1. Schematic illustration of the preparation of porous polymer microparticles.
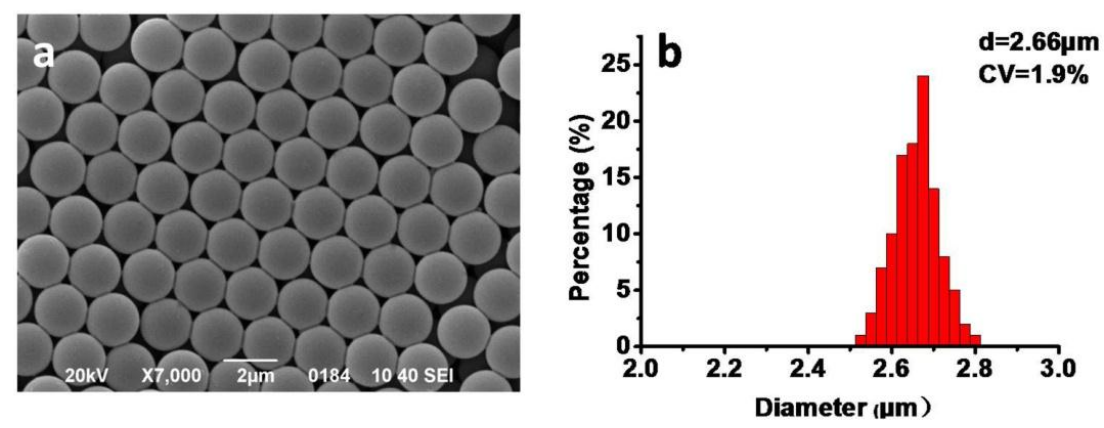

Figure 2. SEM images of $2.7 \mu \mathrm{m}$ PS seed microspheres synthesized by dispersion polymerization (a) and the histogram of the distribution of PS seed microspheres $(\mathbf{b})$. 
Table 1. Preparation conditions of porous polymer microparticles.

\begin{tabular}{cccccc}
\hline Sample & $\begin{array}{c}\text { Toluene } \\
(\mathbf{m L})\end{array}$ & $\begin{array}{c}\text { DBP } \\
(\mathbf{m L})\end{array}$ & $\begin{array}{c}\text { Swelling Temperature } \\
\left({ }^{\circ} \mathbf{C}\right)\end{array}$ & $\begin{array}{c}\text { DVB } \\
(\mathbf{m L})\end{array}$ & $\begin{array}{c}\text { EDMA } \\
(\mathbf{m L})\end{array}$ \\
\hline P(S-DVB)-1 & 0 & 2.4 & 35 & 2.0 & 0 \\
P(S-DVB)-2 & 0.6 & 1.8 & 35 & 2.0 & 0 \\
P(S-DVB)-3 & 1.2 & 1.2 & 35 & 2.0 & 0 \\
P(S-DVB)-4 & 1.8 & 0.6 & 35 & 2.0 & 0 \\
P(S-DVB)-5 & 2.4 & 0 & 35 & 2.0 & 0 \\
P(S-DVB)-6 & 1.2 & 1.2 & 15 & 2.0 & 0 \\
P(S-DVB)-7 & 1.2 & 1.2 & 25 & 2.0 & 0 \\
P(S-DVB)-8 & 1.2 & 1.2 & 45 & 2.0 & 0 \\
P(S-EDMA) & 1.2 & 1.2 & 35 & 0 & 2.0 \\
\hline a Dibutyl phthatate(DBP); divinylbenzene(DVB);
\end{tabular}

${ }^{a}$ Dibutyl phthalate(DBP); divinylbenzene(DVB); ethylene dimethacrylate(EDMA).

The porosity of porous polymer microparticles is greatly influenced by porogens. Figure 3 shows the morphologies of porous polymer microparticles prepared by using different ratios of toluene to DBP as porogens. When only DBP was applied, no pores were observed on the surface of the microparticles (Figure 3a). When the toluene ratio was increased, different sizes of pores with uniform distribution appeared on the surface of the microparticles (Figure 3b-d). When only toluene was used, a few pores were observed (Figure 3e). The BET (the abbreviation of Brunauer, Emmett and Teller) (Figure 3f) result showed that the largest surface area was obtained when the toluene to DBP ratio was 3:1.
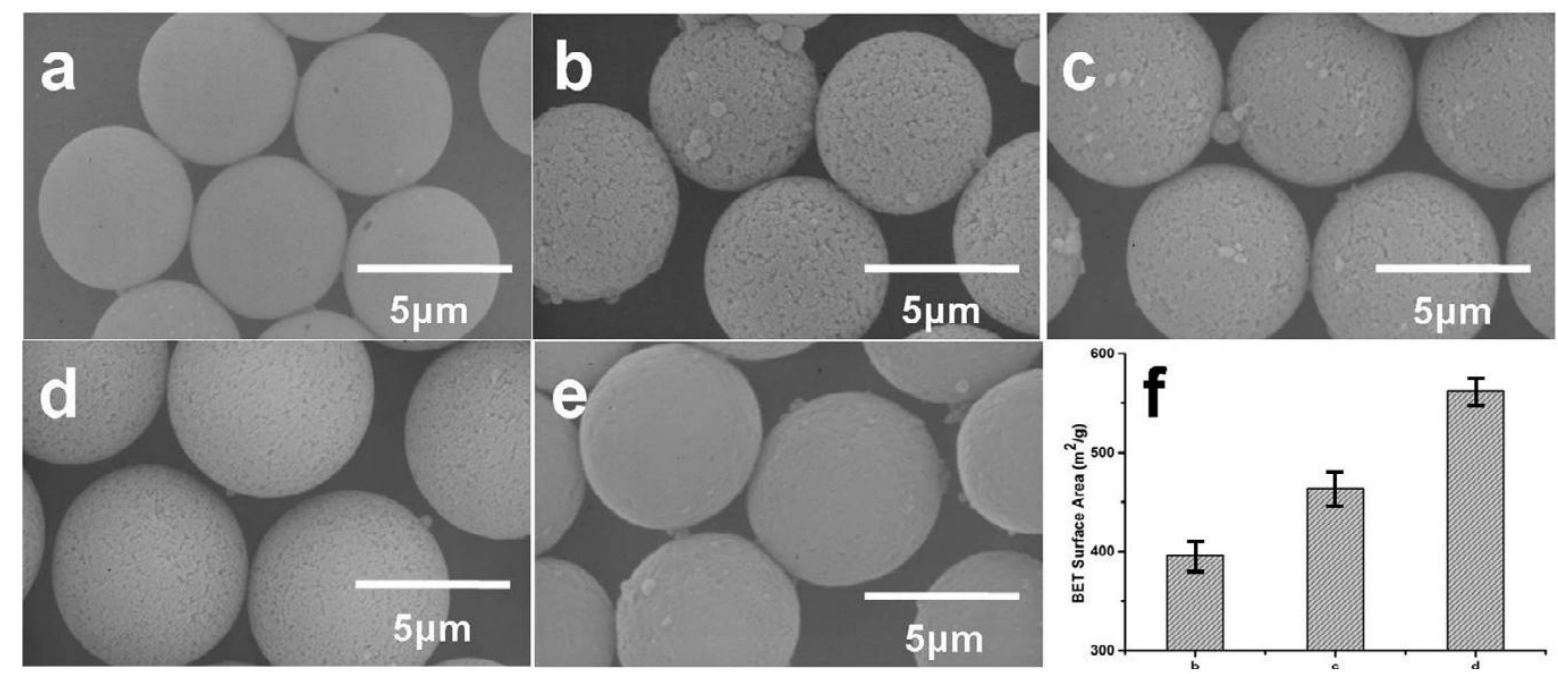

Figure 3. SEM images of porous $\mathrm{P}(\mathrm{S}-\mathrm{DVB})$ microparticles synthesized by using different volume ratios of toluene to DBP: (a) 0:2.4; (b) 0.6:1.8; (c) 1.2:1.2; (d) 1.8:0.6; (e) 2.4:0; (f) the BET surface areas of b, $c$ and d.

The swelling temperature can also influence the morphology of porous $\mathrm{P}(\mathrm{S}-\mathrm{DVB})$ microparticles. As shown in Figure 4, porous $\mathrm{P}(\mathrm{S}-\mathrm{DVB})$ microparticles have the roughest surface when $25{ }^{\circ} \mathrm{C}$ of swelling temperature is applied. A smoother surface and smaller pore size were generated by either decreasing or increasing the swelling temperature. Temperature generally has a great impact on the swelling kinetics. PS seeds might not be well swelled by porogens and monomers under low temperature, leading to dense porous structures. On the contrary, high temperature would accelerate prepolymerization of monomers during swelling, leading to a smoother surface and smaller pore size.

Using different crosslinking agents for synthesizing porous $\mathrm{P}(\mathrm{S}-\mathrm{DVB})$ microparticles presents different morphologies. Figure 5 shows the SEM and TEM images of porous particles that were synthesized by using different crosslinking agents. We can see that the porous microparticles have larger pore size when ethylene dimethacrylate (EDMA) is used as a crosslinker, while the microparticles 
have more uniform pore distribution when DVB is used as a crosslinker. The miscibility and phase separation difference of PS with EDMA and DVB may be the main reason behind this phenomenon.

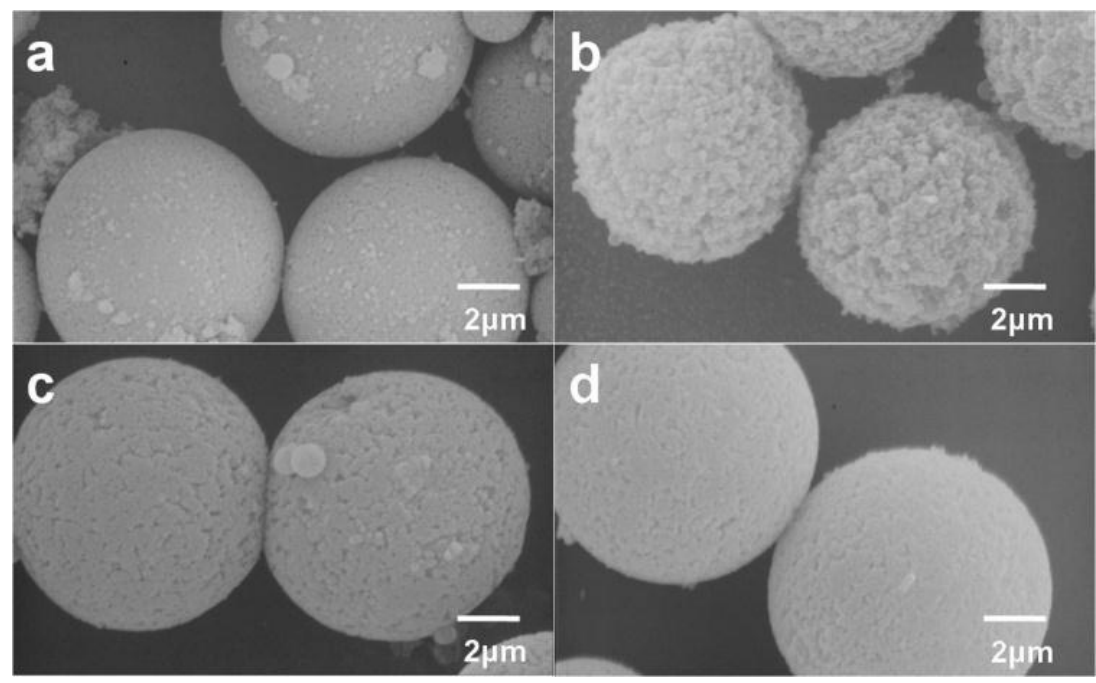

Figure 4. SEM images of the porous $\mathrm{P}(\mathrm{S}-\mathrm{DVB})$ microparticles synthesized by applying different swelling temperatures: (a) $15{ }^{\circ} \mathrm{C}$; (b) $25^{\circ} \mathrm{C}$; (c) $35^{\circ} \mathrm{C}$; (d) $45^{\circ} \mathrm{C}$.

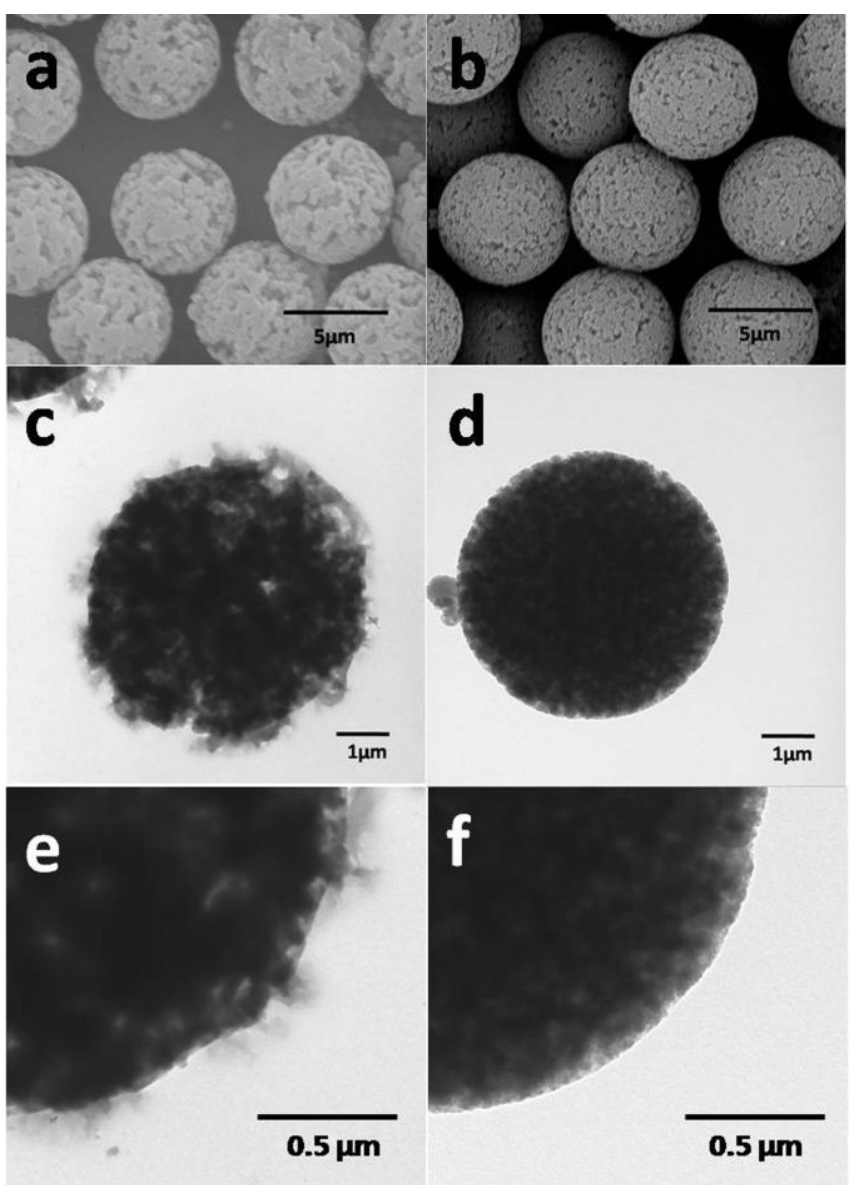

Figure 5. SEM and TEM images of porous particles prepared by using different crosslinking agents: $(\mathbf{a}, \mathbf{c}, \mathbf{e})$ EDMA; $(\mathbf{b}, \mathbf{d}, \mathbf{f})$ DVB. 


\subsection{Porosity}

The surface areas are calculated from $\mathrm{N}_{2}$ sorption isotherms by utilizing the BET method (Figure 6). The specific surface area of the porous P(S-DVB)-3 and P(S-EDMA) microparticles are $464 \mathrm{~m}^{2} / \mathrm{g}$ and $37 \mathrm{~m}^{2} / \mathrm{g}$, respectively, which shows that the crosslinkers have a great impact on the porosity of porous polymer particles. The highest specific surface area can reach $562 \mathrm{~m}^{2} / \mathrm{g}$ of porous $\mathrm{P}(\mathrm{S}-\mathrm{DVB})-4$ microparticles calculated by using the BET method. The average pore size of the $\mathrm{P}(\mathrm{S}-\mathrm{DVB})-3$ and $\mathrm{P}(\mathrm{S}-\mathrm{EDMA})$ are $10 \mathrm{~nm}$ and $18 \mathrm{~nm}$, respectively. The hysteresis loops at moderate to high relative pressure, as shown in Figure 6, indicate mesoporous structures of porous P(S-DVB)-3 and P(S-EDMA) microparticles.
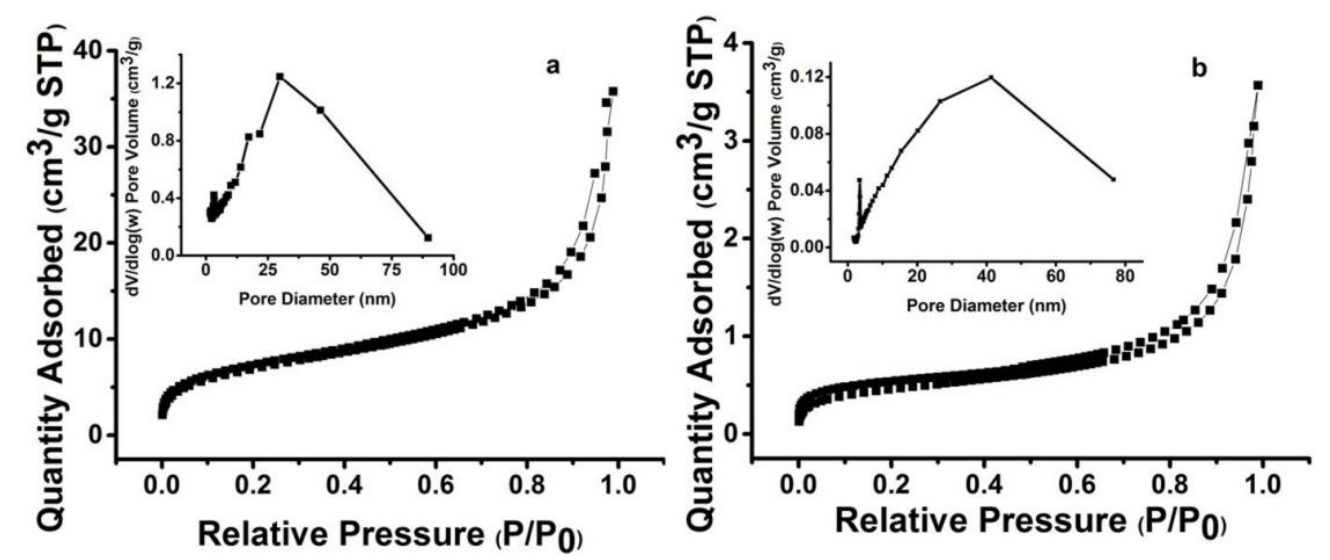

Figure 6. Nitrogen adsorption-desorption isotherms of $\mathrm{P}(\mathrm{S}-\mathrm{DVB})-3$ (a) and P(S-EDMA) (b). Insets are the distributions of pore size.

\subsection{DR-Modified P(S-DVB) Microparticles}

DR-modified porous P(S-DVB) microparticles were synthesized by following the routes in Figure 7. The porous $\mathrm{P}(\mathrm{S}-\mathrm{DVB})$ microparticles were first sulfonated by concentrated sulfuric acid to form negatively charged porous microparticles, and the positively charged DR was coated onto the surface of porous microparticles via electrostatic interaction. The electrostatic interaction was completely transformed into stable covalent bonds after UV light treatment. The DR was first converted into its phenyl cationic form after releasing $\mathrm{N}_{2}$ upon UV irradiation, then a $\mathrm{S}_{\mathrm{N}} 1$ type of nuclear displacement by sulfonate occurs [33]. The specific surface areas of DR-modified porous P(S-DVB) microparticles $\left(396 \mathrm{~m}^{2} / \mathrm{g}\right)$ and the distribution of pore size are shown in Figure S1.

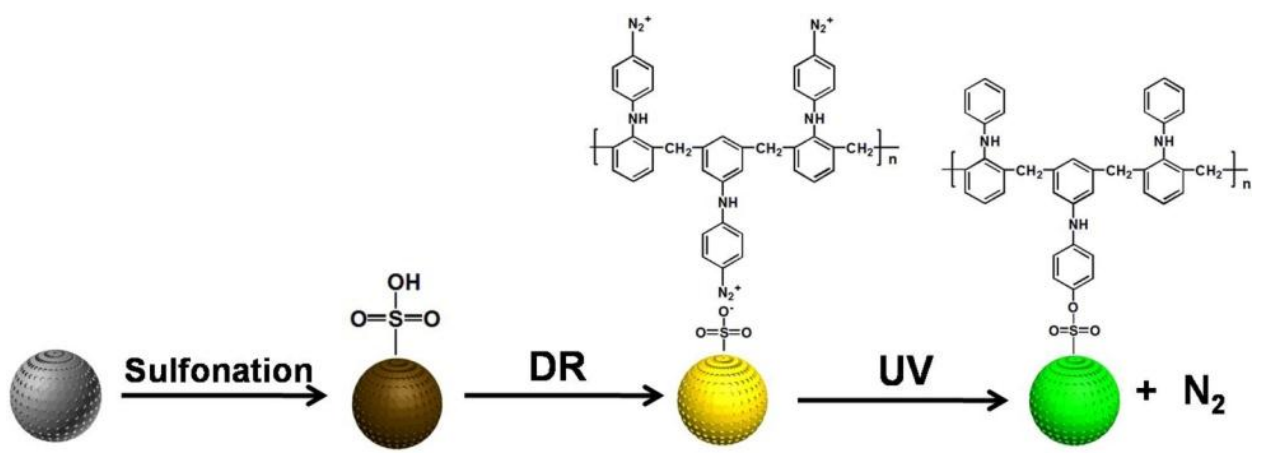

Figure 7. Schematic illustration of the diazoresin (DR) modification of $\mathrm{P}(\mathrm{S}-\mathrm{DVB})$.

As shown in Figure 8, the characteristic absorption peaks of sulfonic acid groups at 1180 and $1089 \mathrm{~cm}^{-1}$ indicate the successful sulfonation of porous $\mathrm{P}(\mathrm{S}-\mathrm{DVB})$ microparticles. The absorption 
peak at $1265 \mathrm{~cm}^{-1}$ can be assigned to the stretching vibration of N-H derived from DR; the peaks at $1450 \mathrm{~cm}^{-1}$ and $1500 \mathrm{~cm}^{-1}$ were assigned to the stretching vibration of the aromatic ring of DR, demonstrating the presence of DR after the modification.

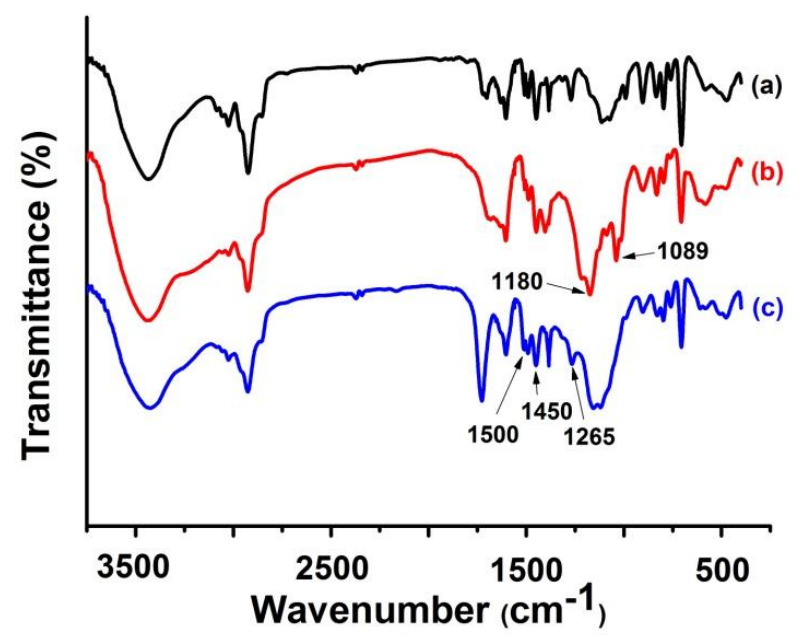

Figure 8. Fourier Transform Intrared(FT-IR) spectra of porous P(S-DVB) microparticles (a); sulfonated $\mathrm{P}(\mathrm{S}-\mathrm{DVB})$ microparticles (b); and DR-modified P(S-DVB) microparticles (c).

\subsection{Chromatographic Performance}

To investigate their chromatographic performance, the porous $\mathrm{P}(\mathrm{S}-\mathrm{DVB})$ microparticles were packed into stainless-steel chromatographic columns. Figure 9 shows the back pressure of columns packed with $\mathrm{P}(\mathrm{S}-\mathrm{DVB})-3$ and $\mathrm{P}(\mathrm{S}-\mathrm{DVB})-4$ at different flow rates. The back pressure demonstrates a decent linearity with the stream flow rate in the acetonitrile $(\mathrm{ACN})$-water mixture $(v / v=7: 3)$. The back pressure of the column packed with $\mathrm{P}(\mathrm{S}-\mathrm{DVB})-4$ is lower than that of $\mathrm{P}(\mathrm{S}-\mathrm{DVB})-3$, because the average pore size of $\mathrm{P}(\mathrm{S}-\mathrm{DVB})-4(\sim 18 \mathrm{~nm})$ is bigger than that of $\mathrm{P}(\mathrm{S}-\mathrm{DVB})-3(\sim 10 \mathrm{~nm})$.

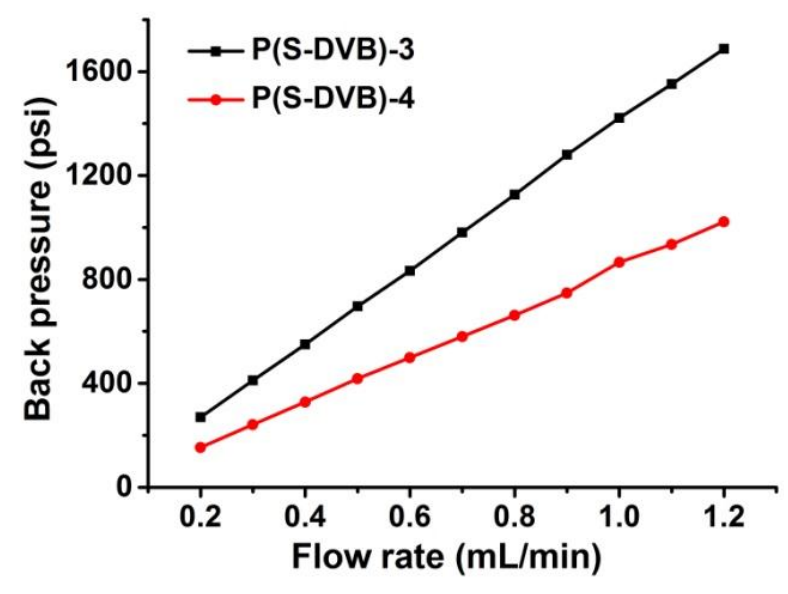

Figure 9. Back pressure of columns packed with different porous polymer microparticles: column, $75 \mathrm{~mm} \times 4.6 \mathrm{~mm}$ Inner Diameter(I.D.); mobile phase, ACN-water mixture $(v / v=7: 3)$.

The mixture of uracil, toluene, naphthalene and fluorene were separated by the packed column with various permeable polymer microparticles. As shown in Figure 10, the column packed with $\mathrm{P}(\mathrm{S}-\mathrm{DVB})-4$ isolates the mixture faster than the column packed with $\mathrm{P}(\mathrm{S}-\mathrm{DVB})-3$ due to the higher specific surface area of the former. Because the P(S-DVB) -4 microparticle performed better than the $\mathrm{P}(\mathrm{S}-\mathrm{DVB})-3$ microparticle, it was selected for the DR surface modification and the following chromatographic tests. 


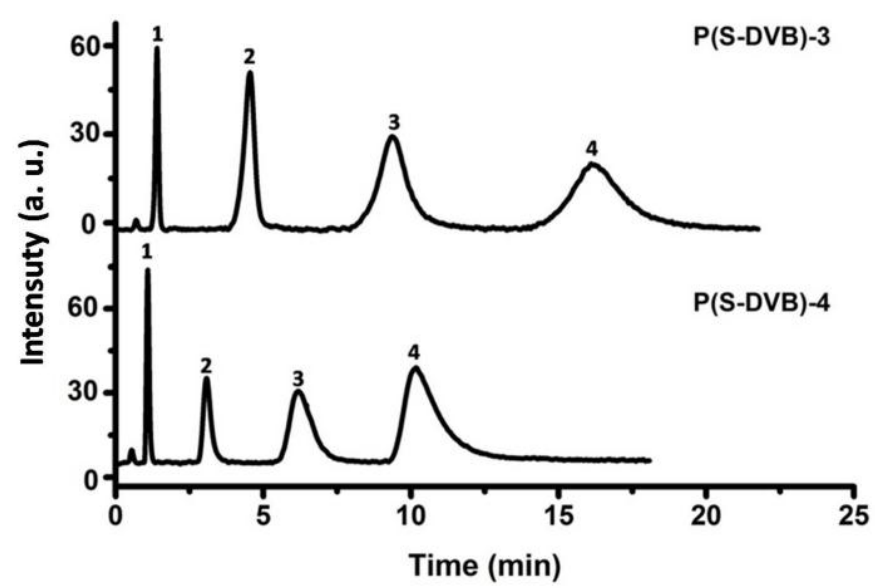

Figure 10. Chromatograms for the separation of benzene analogues on the porous $\mathrm{P}(\mathrm{S}-\mathrm{DVB})$ column: column, $75 \mathrm{~mm} \times 4.6 \mathrm{~mm}$ I.D.; injection size, $3 \mu \mathrm{L}$; flow rate: $0.5 \mathrm{~mL} / \mathrm{min}$; mobile phase, ACN-water mixture $(v / v=7: 3)$; elution order: (1) uracil, (2) toluene, (3) naphthalene, (4) fluorene.

Depending on the chemical structure of DR and mobile phase composition, the DR-modified porous $\mathrm{P}(\mathrm{S}-\mathrm{DVB})-4$ stationary phase performed different separation mechanisms, including reversed phase (RP) and hydrophilic interactions. As shown in Figure 11, the benzene analogues were also successfully separated by porous P(S-DVB)-DR microparticles. The affinity interaction between benzene rings of DR and the benzene analogues make the separation practical. Compared with Figure S2, the separation performance of the P(S-DVB)-DR column is better than a commercial C18 column (Agela Technologies, S185006, Wilmington, DE, USA) at the same $75 \mathrm{~mm}$ column length.

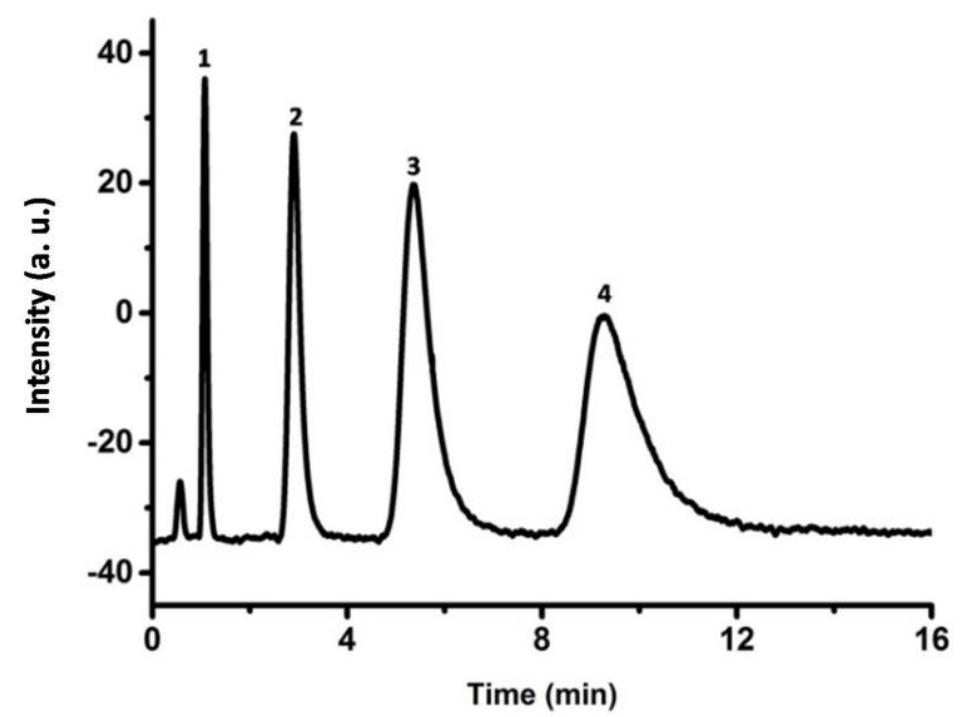

Figure 11. Chromatograms for the separation of benzene analogues on the porous $\mathrm{P}(\mathrm{S}-\mathrm{DVB}) \mathrm{DR}$ column: column, $75 \mathrm{~mm} \times 4.6 \mathrm{~mm}$ I.D.; injection size, $3 \mu \mathrm{L}$; flow rate: $1.0 \mathrm{~mL} / \mathrm{min}$; mobile phase, ACN-water mixture ( $v / v=7: 3$ ); elution order: (1) uracil, (2) toluene, (3) naphthalene, (4) fluorene.

Table 2 shows that the run-to-run $(n=5)$ relative standard deviation(RSD) of retention time for the benzene analogues was less than $1 \%$, day-to-day $(n=7)$ RSD was less than $2.5 \%$, and column-to-column $(n=5)$ RSD was less than $3.5 \%$. After a continuous 100 times running in one column, the RSDs of retention time for the benzene analogues were all less than $2.5 \%$, and the separation performance of the $\mathrm{P}(\mathrm{S}-\mathrm{DVB})-\mathrm{DR}$ column was not deteriorated. Therefore, the $\mathrm{P}(\mathrm{S}-\mathrm{DVB})-\mathrm{DR}$ columns demonstrated very good stability and repeatability. 
Table 2. Separation performance of the P(S-DVB)-DR column for benzene analogues.

\begin{tabular}{ccccc}
\hline \multicolumn{5}{c}{ Retention Time RSD (\%) } \\
\hline $\begin{array}{c}\text { Benzene } \\
\text { Analogues }\end{array}$ & $\begin{array}{c}\text { Run to Run } \\
(\boldsymbol{n}=\mathbf{5})\end{array}$ & $\begin{array}{c}\text { Day to Day } \\
(\boldsymbol{n}=\mathbf{7})\end{array}$ & $\begin{array}{c}\text { Column to Column } \\
(\boldsymbol{n}=\mathbf{5})\end{array}$ & $\begin{array}{c}\text { Continuous 100 } \\
\text { Times Running }\end{array}$ \\
\hline Uracil & 0.56 & 1.54 & 2.21 & 1.65 \\
Toluene & 0.79 & 1.65 & 2.89 & 1.86 \\
Naphthalene & 0.81 & 1.87 & 3.32 & 2.16 \\
Fluorene & 0.86 & 2.23 & 3.47 & 2.32 \\
\hline \multicolumn{5}{c}{}
\end{tabular}

With the introduction of hydrophilic secondary amine groups on the surface of the P(S-DVB)-4 particles, a series of organic acids were baseline separated on the P(S-DVB)-DR column (Figure 12b). The bare P(S-DVB)-4 column (Figure 12a) was used to compare with the P(S-DVB)-DR column. As shown in Figure 12b, the P(S-DVB)-DR column could effectively separate four kinds of organic acids. However, for the bare $\mathrm{P}(\mathrm{S}-\mathrm{DVB})-4$ column, the resolution decreased significantly (Figure 12a). The chemical structure of DR on the surface of $\mathrm{P}(\mathrm{S}-\mathrm{DVB})-4$ particles enhanced the interactions between organic acids and the stationary phase so that the separation was much more efficient than bare P(S-DVB)-4 particles. Compared with Figure S3, the separation performance of the P(S-DVB)-DR column is better than a commercial C18 column (Agela Technologies, S185006) at the same $75 \mathrm{~mm}$ column length.

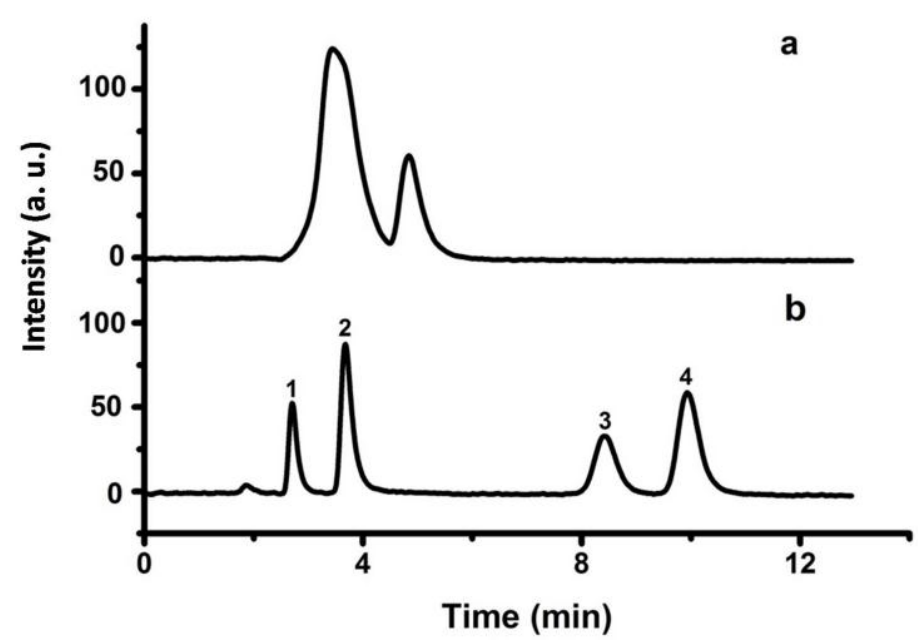

Figure 12. Chromatograms for the separation of four organic acids on the P(S-DVB)-4 column (a) and P(S-DVB)-DR (b) column: column, $75 \mathrm{~mm} \times 4.6 \mathrm{~mm}$ I.D.; flow rate, $0.5 \mathrm{~mL} / \mathrm{min}$; injection size, $1 \mathrm{~mL}$; mobile phase, phosphate buffer $(\mathrm{pH}=4)$ and methanol ( $v / v=85: 15)$; elution order: (1) formic acid, (2) acetic acid, (3) lactic acid, (4) benzoic acid.

Table 3 shows that the run-to-run $(n=5)$ RSD of retention time for the organic acids was less than $1 \%$, day-to-day $(n=7)$ RSD was less than $2 \%$, and column-to-column $(n=5)$ RSD was less than $3.5 \%$. After a continuous 100 times running in one column, the RSDs of retention time for the organic acids were all less than $2.5 \%$, and the separation performance of the P(S-DVB)-DR column was not deteriorated. Thereby, the DR-modified P(S-DVB)-4 particles were robust and had excellent performance in mix-mode HPLC separations.

According to the excellent performance of the $\mathrm{P}(\mathrm{S}-\mathrm{DVB})-\mathrm{DR}$ column in the separation of benzene analogues, $\mathrm{C}_{60}$ and $\mathrm{C}_{70}$ - class of special nanomaterials - were also separated in the P(S-DVB)-DR column using hexane and isopropanol $(v / v=1: 3.5)$ as eluent. Considering that both $\mathrm{C}_{60}$ and $\mathrm{C}_{70}$ have carbon ring structures, the $\pi-\pi$ affinity interactions between benzene rings of $\mathrm{P}(\mathrm{S}-\mathrm{DVB})$-DR 
particles and the carbon rings of fullerenes make the separation practical. As shown in Figure 13, $\mathrm{C}_{60}$ and $\mathrm{C}_{70}$ were successfully separated on the P(S-DVB)-DR column (Figure 13b), while they could not be separated on the bare P(S-DVB)-4 column (Figure 13a). Therefore, the DR surface modification contributed to the high efficiency of the $\mathrm{P}(\mathrm{S}-\mathrm{DVB})-4$ stationary phase for mix-mode separation. In the columns, $\mathrm{C}_{60}$-having less $\pi-\pi$ bondings than $C_{70}-$ was first eluted due to the weaker interaction with the benzene rings of DR. Compared with Figure S4, the separation performance of the P(S-DVB)-DR column is better than a commercial C18 column (Agela Technologies, S185006) at the same $75 \mathrm{~mm}$ column length.

Table 3. Separation performance of the P(S-DVB)-DR column for organic acids.

\begin{tabular}{ccccc}
\hline \multicolumn{5}{c}{ Retention Time RSD (\%) } \\
\hline Organic Acids a & $\begin{array}{c}\text { Run to Run } \\
(\boldsymbol{n}=\mathbf{5})\end{array}$ & $\begin{array}{c}\text { Day to Day } \\
(\boldsymbol{n}=\mathbf{7})\end{array}$ & $\begin{array}{c}\text { Column to Column } \\
(\boldsymbol{n}=\mathbf{5})\end{array}$ & $\begin{array}{c}\text { Continuous 100 } \\
\text { Times Running }\end{array}$ \\
\hline Formic Acid & 0.81 & 1.84 & 2.46 & 2.12 \\
Acetic Acid & 0.75 & 1.65 & 2.32 & 1.93 \\
Lactic Acid & 0.98 & 1.98 & 3.43 & 2.43 \\
Benzoic Acid & 0.92 & 1.89 & 3.12 & 2.24 \\
\hline
\end{tabular}

a Separation conditions: the same as Figure 12.

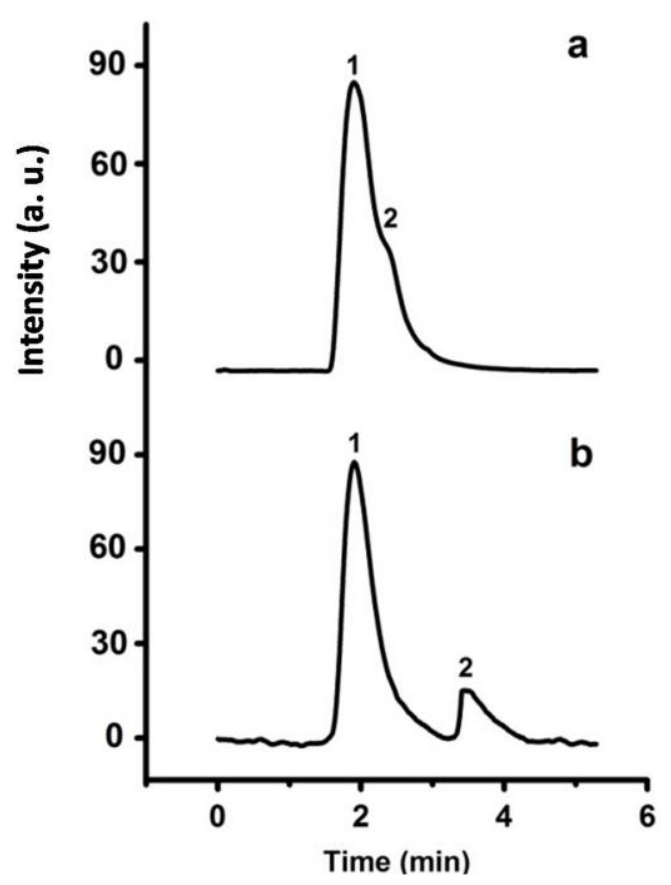

Figure 13. Chromatograms for the separation of $C_{60}$ and $C_{70}$ on the porous $P(S-D V B)-4$ column (a) and $\mathrm{P}(\mathrm{S}-\mathrm{DVB})$-DR (b) column: column, $75 \mathrm{~mm} \times 4.6 \mathrm{~mm}$ I.D.; injection size, $3 \mu \mathrm{L}$; flow rate: $0.5 \mathrm{~mL} / \mathrm{min}$; mobile phase, hexane and isopropanol $(v / v=1: 3.5)$; elution order: (1) $\mathrm{C}_{60}$, (2) $\mathrm{C}_{70}$.

\section{Materials and Methods}

\subsection{Materials}

Styrene (St, 99\%), DVB (99\%), AIBN (98\%), sodium dodecylsulfate (SDS, 99\%), DBP (99\%), toluene (99.5\%), naphthalene (99.5\%), ethanol (99.5\%), ACN (99.9\%), isopropanol (99.7\%) and THF (99\%), copper chloride $\left(\mathrm{CuCl}_{2}, 99 \%\right)$ were purchased from Tianjin Chemical company. Poly(N-vinylpyrrolidone) (PVP, $\left.\mathrm{M}_{\mathrm{n}}=40,000\right)$ and polyvinyl alcohol (PVA-124, degree of polymerization 
2400, degree of hydrolysis $98 \%$ ) were provided by Sinopharm Chemical Reagent Company (Beijing, China). Uracil (99\%) and fluorene (99.5\%) were purchased from Aladdin Chemical Reagent Company (Shanghai, China). Benzoyl peroxide (BPO, 95\%) was bought from Tianjin Beichen Chemical Company (Tianjin, China). DVB and St were used after vacuum distillation. DR $\left(\mathrm{M}_{n}=2500\right)$ was synthesized by polycondensation of diphenylamine-4-diazonium salt and paraformaldehyde in concentrated $\mathrm{H}_{2} \mathrm{SO}_{4}$ according to a method described elsewhere [34].

\subsection{Preparation of PS Seed Particles}

Monodisperse PS seed particles with an average diameter of $2.7 \mu \mathrm{m}$ were synthesized by a reported dispersion polymerization method [35]. The polymerization was carried out in a three-necked flask with mechanical stirring at $300 \mathrm{rpm}$ under nitrogen atmosphere. In the flask, $1.35 \mathrm{~g}$ of PVP was dissolved in $80 \mathrm{~g}$ of ethanol. An amount of $15 \mathrm{~g}$ of styrene and $0.44 \mathrm{~g}$ of AIBN were also added into the flask after increasing the bath temperature to $70^{\circ} \mathrm{C}$. After $24 \mathrm{~h}$ of polymerization, the PS seed particles were separated through centrifugation and washed with ethanol three times, and then dried under vacuum at ambient temperature.

\subsection{Synthesis of Porous Polymer Microparticles}

Porous polymer particles were synthesized by two-step seeded swelling polymerization techniques as given below: seed particles $(2.7 \mu \mathrm{m}, 0.26 \mathrm{~g})$ were ultra-sonicated to be well dispersed in $10 \mathrm{~mL}$ distilled water. A mixture of $1.2 \mathrm{~mL}$ toluene and $1.2 \mathrm{~mL}$ DBP was emulsified in $20 \mathrm{~mL} 0.375 \mathrm{wt} \%$ SDS aqueous solution in an ultrasonic bath $(10 \mathrm{~min}, 100 \mathrm{~W})$ separately. The dispersion of PS particles and emulsion of porogens were mixed and mechanically stirred at $300 \mathrm{rpm}$ in an oil-bath at $35^{\circ} \mathrm{C}$ for $24 \mathrm{~h}$. A mixture of $0.6 \mathrm{~mL}$ styrene and $2.0 \mathrm{~mL}$ DVB containing $0.12 \mathrm{~g}$ BPO was emulsified in $30 \mathrm{~mL}$ $0.25 \%$ SDS aqueous solution using ultrasonic agitation $(10 \mathrm{~min}, 100 \mathrm{~W})$. The prepared emulsion was added into the swelled PS dispersion solution and stirred for another $24 \mathrm{~h}$. At the end, $3.5 \mathrm{~mL}$ of $10 \%$ PVA aqueous solution was added into the dispersion. At the polymerization stage, the dispersion was purged with nitrogen for $30 \mathrm{~min}$. Polymerization of the monomer phase in the swollen seed particles was carried out at $70{ }^{\circ} \mathrm{C}$ under mechanical stirring of $120 \mathrm{rpm}$ for $24 \mathrm{~h}$. After polymerization, the particles were isolated, washed with ethanol three times by using a centrifugation-decantation protocol, and then extracted with THF at $60{ }^{\circ} \mathrm{C}$ for $12 \mathrm{~h}$ to remove linear polymer and swelling agent completely. After centrifugation, the porous microparticles were washed with ethanol and dried in a vacuum oven.

\subsection{Preparation of DR-Modified Porous $P(S-D V B)$ Microparticles}

Modification of porous P(S-DVB) microspheres with DR was carried out as follows: the porous $\mathrm{P}(\mathrm{S}-\mathrm{DVB})$ microparticles $(0.5 \mathrm{~g})$ were first sulfonated by concentrated sulfuric acid $(20 \mathrm{~mL})$ at $40{ }^{\circ} \mathrm{C}$ for $4 \mathrm{~h}$. The sulfonated porous $\mathrm{P}(\mathrm{S}-\mathrm{DVB})$ microspheres were then added into $10 \mathrm{~mL}$ aqueous solution of DR $(4 \mathrm{mg} / \mathrm{mL})$ under magnetic stirring. The modified porous microspheres were washed with deionized water three times by centrifugation, and this process was repeated another three times in order to ensure that DR was completely coated onto the porous microspheres. After being dried under vacuum at room temperature for $12 \mathrm{~h}$, the DR-coated $\mathrm{P}(\mathrm{S}-\mathrm{DVB})$ microspheres were exposed under $365 \mathrm{~nm}$ UV light with an intensity of $350 \mathrm{~mW} / \mathrm{cm}^{2}$ for $15 \mathrm{~min}$. Consequently, DR was covalently linked to the surface of porous P(S-DVB) microspheres [36], and the yield was $95 \%$.

\subsection{Characterization}

The surface morphology and structure of PS seed particles and porous $\mathrm{P}(\mathrm{S}-\mathrm{DVB})$ spheres were observed by using scanning electron microscopy (SEM, JEOL JSM-6309LV, Beijing, China) and transmission electron microscopy (TEM, JEOL JEM-1200). An accelerated surface area and porosimetry analyzer (ASAP, Micromeritics 2020, Micromeritics Instrument Corp., Shanghai, China) was used 
for the BET tests. Chromatographic study was carried out using a HPLC (SEV P500, Qingdao Qicai Sunshine Information Technology Co., Ltd., Qingdao, China) equipped with a UV detector.

\subsection{Chromatography}

The monodisperse porous PS microparticles were dispersed in isopropanol/methanol $(v / v=1: 1)$ and packed into stainless-steel columns $(75 \mathrm{~mm} \times 4.6 \mathrm{~mm}$, I.D.) by applying a chromatographic column packing machine (GLK 2000, GALAK, Shanghai Yuhong Energy Saving Technology Co., Ltd., Shanghai, China) under a pressure of $18 \mathrm{MPa}$. The column was connected to the HPLC framework and flushed with methanol at a flow rate of $0.8 \mathrm{~mL} / \mathrm{min}$ for $2 \mathrm{~h}$ to equilibrate the column until a constant UV baseline was obtained. A mixture of uracil, toluene, naphthalene and fluorene was separated in the HPLC column packed with porous P(S-DVB)-4 and P(S-DVB)-DR microparticles at a flow rate of $0.5-1.0 \mathrm{~mL} / \mathrm{min}$ at room temperature applying a UV detecting wavelength of $254 \mathrm{~nm}$ with ACN-water mixture $(v / v=7: 3)$ as eluent. The organic acids mixture of formic acid, acetic acid, lactic acid and benzoic acid was also separated on the above two kinds of column under a flow rate of $0.5 \mathrm{~mL} / \mathrm{min}$ at room temperature with phosphate buffer $(\mathrm{pH}=4)$ and methanol $(v / v=85: 15)$ as mobile phase at a detecting wavelength of $210 \mathrm{~nm}$. In addition, $\mathrm{C}_{60}$ and $\mathrm{C}_{70}$ were separated on the modified $\mathrm{P}(\mathrm{S}-\mathrm{DVB})-\mathrm{DR}$ column using hexane and isopropanol $(v / v=1: 3.5)$ as the mobile phase at a flow rate of $0.5 \mathrm{~mL} / \mathrm{min}$ at a detecting wavelength of $290 \mathrm{~nm}$.

\section{Conclusions}

In this paper, porous $\mathrm{P}(\mathrm{S}-\mathrm{DVB})$ microparticles with high specific surface areas were successfully synthesized by the two-step activated swelling method. The effects of the porogens, swelling temperature and crosslinking agent were investigated in detail. The largest surface area is obtained when the toluene to DBP porogens ratio is 3:1, and porous $\mathrm{P}(\mathrm{S}-\mathrm{DVB})$ microparticles have the roughest surface when a swelling temperature of $25{ }^{\circ} \mathrm{C}$ is applied. The obtained $\mathrm{P}(\mathrm{S}-\mathrm{DVB})$ particles were modified by sulfonation and self-assembly positive charged photosensitive DR on the surface. After treatment with UV light, the ionic bonding between sulfonated P(S-DVB) and DR was converted into covalent bonding through a unique photochemistry reaction of DR. Depending on the chemical structure of DR and mobile phase composition, the P(S-DVB)-DR stationary phase performed different separation mechanisms, including reversed phase and hydrophilic interactions. Thus, a variety of baseline separations of benzene analogues and organic acids was achieved by using the P(S-DVB)-DR particles as packing materials in HPLC. According to the $\pi-\pi$ interactional difference between carbon rings of fullerenes and benzene rings of $\mathrm{P}(\mathrm{S}-\mathrm{DVB})-\mathrm{DR}, \mathrm{C}_{60}$ and $\mathrm{C}_{70}$ were also successfully separated in the HPLC column packed with P(S-DVB)-DR particles. Compared with bare P(S-DVB) packing material, the DR surface modification contributed to the high efficiency of the P(S-DVB) stationary phase for mix-mode separation.

Supplementary Materials: The following are available online at www.mdpi.com/1996-1944/10/4/440/s1, Figure S1: Nitrogen adsorption-desorption isotherms of P(S-DVB)-DR. Inset is the distributions of pore size. Figure S2: Separation on C18 column for benzene analogues. Column, $75 \mathrm{~mm} \times 4.6 \mathrm{~mm}$ I.D.; injection size, $3 \mu \mathrm{L}$; mobile phase, methanol.

Acknowledgments: This work is financially supported by the National Natural Science Foundation of China $(21375069,21574072,21675091,21404065)$, the Natural Science Foundation for Distinguished Young Scientists of Shandong Province (JQ201403), the Taishan Young Scholar Program of Shandong Province (tsqn20161027), the Key Research and Development Project of Shandong Province (2016GGX102028, 2016GGX102039), the Project of Shandong Province Higher Educational Science and Technology Program (J15LC20), the Scientific Research Foundation for the Returned Overseas Chinese Scholars of State Education Ministry (20111568), the People's Livelihood Science and Technology Project of Qingdao (166257nsh), and the Postdoctoral Scientific Research Foundation of Qingdao(2015128).

Author Contributions: H.C., B.Y. and T.X. conceived and designed the experiments. T.X. and B.Y. conducted the experiments. H.C., B.Y. and Q.P. discussed the results. T.X., B.Y. and M.U. wrote the manuscript.

Conflicts of Interest: The authors declare no conflict of interest. 


\section{References}

1. Ugelstad, J.; Kaggerud, K.H.; Hansen, F.K.; Berge, A. Absorption of low molecular weight compounds in aqueous dispersions of polymer-oligomer particles. A two step swelling process of polymer particles giving an enormous increase in absorption capacity. Macromol. Chem. Phys. 1979, 180,737-744. [CrossRef]

2. Ellingsen, T.; Aune, O.; Ugelstad, J.; Hagen, S. Monosized stationary phases for chromatography. J. Chromatogr. 1990, 535, 147-161. [CrossRef]

3. Tuncel, A.; Tuncel, M.; Ergun, B.; Alagoz, C.; Bahar, T. Carboxyl carrying-large uniform latex particles. Colloids Surf. A 2002, 197, 79-94. [CrossRef]

4. Wang, Y.; Wei, C.; Cong, H.; Yang, Q.; Wu, Y.; Su, B.; Zhao, Y.; Wang, J.; Jiang, L. Hybrid top-down/bottom-up strategy using superwettability for the fabrication of patterned colloidal assembly. ACS Appl. Mater. Interfaces 2016, 8, 4985-4993. [CrossRef] [PubMed]

5. Yu, B.; Zhai, F.; Cong, H.; Yang, D. Photosensitive polystyrene/silver bromide hybrid colloidal crystals as recoverable colorimetric naked eye probes for bromine gas sensing. J. Mater. Chem. C 2016, 4, 1386-1391. [CrossRef]

6. Albuszis, M.; Roth, P.J.; Pauer, W.; Moritz, H.U. Macroporous uniform azide-and alkyne-functional polymer microspheres with tuneable surface area: Synthesis, in-depth characterization and click-modification. Polym. Chem. 2014, 5, 5689-5699. [CrossRef]

7. Yu, B.; Sun, X.; Liu, X.; Cong, H.; Wang, Y.; Shu, X.; Yuan, H.; Wang, D.; Tang, J. Microfluidic chip assisted synthesis of monodisperse functional poly (pentaerythritol triacrylate) microspheres. Sci. Adv. Mater. 2015, 7, 964-968. [CrossRef]

8. Qu, J.B.; Huan, G.S.; Chen, Y.L.; Zhou, W.Q.; Liu, J.G.; Huang, F. Coating gigaporous polystyrene microspheres with crosslinked poly (vinyl alcohol) hydrogel as a rapid protein chromatography matrix. ACS Appl. Mater. Interfaces 2014, 6, 12752-12760. [CrossRef] [PubMed]

9. Yu, B.; Cong, H.; Yuan, H.; Liu, X.; Peng, Q.; Zhang, X.; Xu, X.; Tian, C.; Yang, R.; Yang, S. Preparation of doughnut-like nanocomposite colloidal crystal particles with enhanced light diffraction using drying self-assembly method. Curr. Nanosci. 2015, 11, 161-165. [CrossRef]

10. Roman, F.; Colomer, P.; Calventus, Y.; Hutchinson, M. Study of the Molecular Dynamics of Multiarm Star Polymers with a Poly(ethyleneimine) Core and Poly(lactide) Multiarms. Materials 2017, 10, 127-145. [CrossRef]

11. Yu, B.; Tian, C.; Cong, H.L.; Xu, T. Synthesis of monodisperse poly(styrene-co-divinylbenzene) microspheres with binary porous structures and application in high-performance liquid chromatography. J. Mater. Sci. 2016, 51, 5240-5251. [CrossRef]

12. Li, Y.; Gao, F.; Wei, W.; Qu, J.B.; Ma, G.H.; Zhou, W.Q. Pore size of macroporous polystyrene microspheres affects lipase immobilization. J. Mol. Catal. B 2010, 66, 182-189. [CrossRef]

13. Liu, Q.; Li, Y.; Shen, S.; Xiao, Q.; Chen, L.; Ou, B.; Ding, Y. Preparation and characterization of crosslinked polymer beads with tunable pore morphology. J. Appl. Polym. Sci. 2011, 121, 654-659. [CrossRef]

14. Okay, O. Macroporous copolymer networks. Prog. Polym. Sci. 2000, 25, 711-779. [CrossRef]

15. Ugelstad, J. Swelling capacity of aqueous dispersions of oligomer and polymer substances and mixtures thereof. Makromol. Chem. 1978, 179, 815-817. [CrossRef]

16. Cheng, C.M.; Micale, F.J.; Vanderhoff, J.W.; El-Asser, M.S. Synthesis and characterization of monodisperse porous polymer particles. J. Polym. Sci. Pol. Chem. 1992, 30, 235-244. [CrossRef]

17. Li, W.H.; Stöver, H.D. Monodisperse cross-linked core-shell polymer microspheres by precipitation polymerization. Macromolecules 2000, 33, 4354-4360. [CrossRef]

18. Wulff, G. Molecular imprinting in cross-linked materials with the aid of molecular templates-a way towards artificial antibodies. Angew. Chem. Int. Ed. 1995, 34, 1812-1832. [CrossRef]

19. Raj, W.R.P.; Sasthav, M.; Cheung, H.M. Polymerization of single-phase microemulsions: Dependence of polymermorphology on microemulsion structure. Polymer 1995, 36, 2637-2646.

20. Omi, S.; Katami, K.; Yamamoto, A.; Iso, M. Synthesis of polymeric microspheres employing SPG emulsification technique. J. Appl. Polym. Sci. 1994, 51, 1-11. [CrossRef]

21. Omi, S. Preparation of monodisperse microspheres using the Shirasu porous glass emulsification technique. Colloids Surf. A 1996, 109, 97-107. [CrossRef] 
22. Wang, Q.C.; Svec, F.; Frechet, J.M. Fine control of the porous structure and chromatographic properties of monodisperse macroporous poly(styrene-co-divinylbenzene) beads prepared using polymer porogens. J. Polym. Sci. Pol. Chem. 1994, 32, 2577-2588. [CrossRef]

23. Lungfiel, K.; Seubert, A. Varying the porous structure of polystyrene/divinylbenzene beads prepared by Ugelstads activated swelling technique and examining its reversed phase HPLC properties. J. Chromatogr. A 2014, 1358, 117-127. [CrossRef] [PubMed]

24. Svec, F.; Frechet, J.M. New designs of macroporous polymers and supports: From separation to biocatalysis. Science 1996, 273, 205-207. [CrossRef] [PubMed]

25. Zhang, J.; Gan, N.; Chen, S.; Pan, M.; Wu, D.; Cao, Y. $\beta$-cyclodextrin functionalized meso-/macroporous magnetic titanium dioxide adsorbent as extraction material combined with gas chromatography-mass spectrometry for the detection of chlorobenzenes in soil samples. J. Chromatogr. A 2015, 1401, $24-32$. [CrossRef] [PubMed]

26. Vaast, A.; Terryn, H.; Svec, F.; Eeltink, S. Nanostructured porous polymer monolithic columns for capillary liquid chromatography of peptides. J. Chromatogr. A 2014, 1374, 171-179. [CrossRef] [PubMed]

27. Tuncel, A.; Tuncel, M.; Salih, B. Electron microscopic observation of uniform macroporous particles. I. Effect of seed latex type and diluent. J. Appl. Polym. Sci. 1999, 71, 2271-2290. [CrossRef]

28. Unsal, E.; Elmas, B.; Camli, S.T.; Tuncel, M.; Senel, S.; Tucel, A. Monodisperse-porous poly (styrene-codivinylbenzene) beads providing high column efficiency in reversed phase HPLC. J. Appl. Polym. Sci. 2005, 95, 1430-1438. [CrossRef]

29. Liang, Y.C.; Svec, F.; Frechet, J.M. Monodisperse polymer beads as packing material for high-performance liquid chromatography. Preparation of macroporous poly(2,3-epoxypropyl vinylbenzyl ether-co-divinylbenzene) beads, their properties, and application to HPLC separations. J. Polym. Sci. Pol. Chem. 1995, 33, 2639-2646. [CrossRef]

30. Petro, M.; Svec, F.; Frechet, J.M. Monodisperse hydrolyzed poly (glycidyl methacrylate-co-ethylene dimethacrylate) beads as a stationary phase for normal-phase HPLC. Anal. Chem. 1997, 69, 3131-3139. [CrossRef] [PubMed]

31. Thao, L.T.S.; Dang, T.T.T.; Khanitchaidecha, W.; Channei, D.; Nakaruk, A. Photocatalatic Degradation of Organic Dye under UV-A Irradiation Using $\mathrm{TiO}_{2}$-Vetiver Multifunctional Nano Particles. Materials 2017, 10 , 122-135. [CrossRef]

32. Tsai, K.Y.; Lin, H.Y.; Chen, Y.W.; Lin, C.Y.; Hsu, T.T.; Kao, C.T. Laser Sintered Magnesium-Calcium Silicate/Poly- $\varepsilon$-Caprolactone Scaffold for Bone Tissue Engineering. Materials 2017, 10, 65-79. [CrossRef]

33. Sun, J.Q.; Wang, Z.Q.; Sun, Y.P.; Zhang, X.; Shen, J.C. Covalently attached multilayer assemblies of diazo-resins and porphyrins. Chem. Commun. 1999, 8, 693-694. [CrossRef]

34. Shi, J.H.; Qin, Y.J.; Luo, H.X.; Guo, Z.X.; Woo, H.S.; Park, D.K. Covalently attached multilayer self-assemblies of single-walled carbon nanotubols and diazoresins. Nanotechnology 2007, 18, 365704-365708. [CrossRef]

35. Yu, B.; Yuan, H.; Wang, D.; Cong, H.L.; Xu, X.D.; Yang, S.J. Fabrication of anisotropic silica hollow microspheres using polymeric protrusion particles as templates. Colloids Polym. Sci. 2014, 292, 2361-2367. [CrossRef]

36. Yu, B.; Shu, X.; Cong, H.L.; Chen, X.; Liu, H.W.; Yuan, H.; Chi, M. Self-assembled covalent capillary coating of diazoresin/carboxyl fullerene for analysis of proteins by capillary electrophoresis and a comparison with diazoresin/graphene oxide coating. J. Chromatogr. A 2016, 1437, 226-233. [CrossRef] [PubMed]

(C) 2017 by the authors. Licensee MDPI, Basel, Switzerland. This article is an open access article distributed under the terms and conditions of the Creative Commons Attribution (CC BY) license (http:/ / creativecommons.org/licenses/by/4.0/). 